\title{
LA METAFÍSICA Y EL AGUJERO DE LA POLÍTICA: EL SENTIDO DE LA TOPOlOGíA, ENTRE LACAN Y HEIDEgGER
}

\author{
Gianfranco Cattaneo ${ }^{1}$
}

\begin{abstract}
Resumen: Tomando como motivo una conjetura de Lacan dirigida a Heidegger, referida a lo que sería la metafísica y lo que determinaría su historia y sus efectos, el presente trabajo pretende poner en relación la topología lacaniana y la topología heideggeriana. Ahí donde Lacan traduce a Heidegger, veremos que lo que asoma, y que parece haber pasado inadvertido, es la cuestión topológica del agujero y los efectos políticos que implica velarlo. En definitiva, cuando se lleva hasta sus últimas consecuencias lo que implica habitar el lenguaje, veremos que el sentido que ambos autores imprimen a su topología, luego de coincidir, diverge.
\end{abstract}

Palabras Clave: Metafísica. Agujero. Política. Sentido. Topología.

\section{INTRODUCCIÓN}

En la Introducción alemana a un primer volumen de los Escritos, Lacan (2012) pretende llamar la atención de su "amigo" Heidegger. Espera que este se detenga "al menos un instante" en aquello que, a su entender, sería "el resorte" de la metafísica. La "idea" de Lacan (2012a, p. 581, nuestra traducción) es que "[...] la metafísica nunca ha sido nada y no podría prolongarse más que al ocuparse de tapar el agujero de la política”. Esta "idea”, sin embargo, considerada en términos generales, no parece particularmente novedosa. Porque lo primero que uno recuerda, cuando lee la expresión "tapar agujeros", es al Freud de la $35^{\circ}$ Conferencia de Introducción al Psicoanálisis, En torno a una Cosmovisión. Allí, haciendo eco de la burla del poeta H. Heine, Freud nos presenta una imagen del filósofo con un gorro de dormir y con una bata andrajosa, dedicado a cubrir los agujeros del edificio universal, con la pretensión de brindar una imagen coherente y sin lagunas del Universo (FREUD, 2010,

${ }^{1}$ Universidad Andrés Bello. Carrera de Psicología. Facultad de Educación y Ciencias Sociales, Santiago - Chile (1) https://orcid.org/0000-0002-4266-0731 E-mail: gcattaneo@unab.cl.

http://doi.org/10.1590/0101-3173.2020.v43esp.10.p123

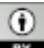

This is an open-access article distributed under the terms of the Creative Commons Attribution License. 
p. 148). El progreso de la ciencia dirá en su texto Lacan, se sostiene de este mismo actuar "metafísico". Justo antes de presentar su "idea", Lacan propone que la ciencia progresa "por la vía de tapar los agujeros". Cuando lo logra, la ciencia se despoja de su sentido. Esto es lo que la convierte en algo seguro para todo el mundo, ya que otorga un fundamento en el que es posible sostenerse. Pero la burla de Heine, que Freud considera tan pertinente y justificada, no puede dejar de considerar la manera en que está vestido el personaje. Su disfraz guarda una estrecha relación con sus pretensiones de coherencia. Porque su vestimenta complementa su gesto respecto del sentido, si uno considera, para completar el cuadro, además de la Conferencia de 1933, otro texto de Freud, más de treinta ańos anterior a esta, que es esa especie de resumen de la Interpretación de los sueños, titulado Sobre el sueño. Respecto del sentido del sueño, la posición de "muchos filósofos", comparada por Freud (2010, p. 617-618) con la posición de los "legos" y la de los "médicos", es considerarlo como una exaltación sublime del espíritu del hombre, con la que se despega de la naturaleza, con miras un estrato más elevado desde donde podrá escrutarla. Es decir, para Freud, los filósofos celebran en sus ropas de dormir, como si recién estuvieran despertando, en vez de interpretar y confrontarse al sentido fragmentario y lagunoso del sueńo; a ojos del psicoanalista, parecen dispuesto a vestir el sentido hasta con pedazos de sus propias ropas.

Ahora bien, continuar con esta apreciación "general", añadiendo a lo que ya dijimos, la coincidencia de que En torno a una Cosmovisión fue pronunciada en 1933, año al que refiere explícitamente Lacan en su Introducción, con el fin de traer a la memoria del "público alemán" al que se dirige su texto, ese momento en que el sentido crítico, que encontró en ellos sus mayores representantes, no pudo evitar el ascenso al poder de un Hitler, nos impediría apreciar la particularidad que comporta la "idea" de Lacan sobre la metafísica. Porque no encontraremos en estas referencias a Freud aquello a lo que se refiere Lacan con el "agujero de la política" que otorga su estatuto a la metafísica y le permite prolongarse como historia; tampoco el que la política sea donde se alcanza la "cima de la futilidad" en lo que respecta a un sentido que, en su opinión, "sólo se capta porque huye"; ni menos llegar a comprender que, lo que Lacan le propone a Heidegger, finalmente, no puede explicarse como si fuera una discusión general entre el psicoanálisis y la filosofía, sino que debe entenderse como una querella particular entre ambos, la que se despliega, y a la vez encuentra su justificación, en el terreno de la topología. Sólo con estas precisiones es que nos será posible entender la indicación "puramente gratuita” de Lacan a su "amigo" Heidegger, transformándola en una pregunta: 
¿qué es un agujero, que hace que la metafísica, al cubrirlo, sea algo? Con ella, esperamos mostrar, en lo que sigue, cómo se reúnen y dialogan, y cómo divergen y se distancian, el sentido de la topología lacaniana y la heideggeriana.

\section{EL “Diálogo": LA TOPOLOGÍA COMO CUESTIÓN DE TRADUCCIÓN}

En La instancia de la letra en el inconsciente o la razón desde Freud, podemos observar cómo, al momento de referirse a la necesidad de un sustrato topológico para pensar la noción de cadena significante, Lacan evoca la topología heideggeriana. Se trata de una traducción, de otra traducción de Heidegger hecha por Lacan, que tiene a la topología como motivo, que sin embargo parece haber pasado desapercibida. Como si todos quienes leímos el escrito de Lacan, hubiésemos quedados encandilados por la luz relampagueante del Logos, impedidos, de alguna manera, de reconocer esta otra traducción. Cuando hacia el final de su texto, Lacan (2008, p. 494) aclara, a quien lo tilda de "neo-heideggeriano", que cuando habla de Heidegger, o más bien, cuando lo traduce, se esfuerza "en dejar a la palabra que él profiere su significancia soberana” ¿es seguro que Lacan se esté refiriendo sólo a la traducción que hizo de Logos? Creemos que no. Porque si consideramos la definición de cadena significante que entrega allí Lacan - "anillos cuyo collar se sella en el anillo de otro collar hecho de anillos" [anneaux dont le collier se scelle dans l'anneau d'un autre collier fait d'anneaux] - (LACAN, 2008, p. 469) no es difícil percatarse que con ella estaría traduciendo, o al menos parafraseando, un tema central de la conferencia de Heidegger $L a$ Cosa y de lo que él mismo llamó topología del ser: el anillar [ring] y el desanillar [entring] del anillo [Ring] que hace al acontecimiento del mundo, abierto en todos los sentidos por la presencia de las cosas como cosas (HEIDEGGER, 2007a, p. 253-254). La importancia que tuvo esta conferencia de Heidegger en el retorno a Freud, cuestión desarrollada extensamente por Jean Allouch en El sexo de la verdad (Allouch, 1999), hablaría a favor de esta propuesta. A lo que puede sumarse, además, el que ya en Función y campo de la palabra y el lenguaje en psicoanálisis podemos encontrar un antecedente para esta traducción/paráfrasis de Lacan. Si queremos alcanzar en el sujeto lo que había antes de los juegos seriales de la palabra - afirma Lacan - lo encontraremos en la muerte, que es donde toda su existencia adquirirá sentido. La muerte es el límite de la función histórica del sujeto "según la fórmula de Heidegger", su "posibilidad absolutamente propia, incondicional, irrebasable". Este sentido mortal con que se retrorae la existencia, revela en la palabra "un centro exterior al lenguaje", que es "más 
que una metáfora y manifiesta una estructura”, diferente de la espacialización de la circunsferencia o de la esfera, "a lo que la lógica simbólica designa topológicamente como un anillo [anneau]", cuya representación intuitiva "es la forma tridimensional del toro" y a la que habria que recurrir en virtud de que su exterioridad periférica y su exterioridad central no constituyen sino una única región" (LACAN, 2008b, p 305-308).

La pregunta por la "cercanía” organiza la reflexión topológica de Heidegger en La Cosa. Que todo haya sido arrastrado hacia el aglutinamiento y la uniforme falta de separación, sentencia Heidegger, no ha aportado ninguna cercanía. A pesar de que el hombre tenga la capacidad técnica de traer todo ante sí en la máxima inmediatez, falta la cercanía de lo que es. El ente queda dislocado de su esencia, porque la cercanía con lo que es no consiste en la reducción o eliminación de las distancias, sino que una relación originaria con el acontecer de las cosas y el mundo. Lo cercano sólo podrá ser experimentado si es el hombre el que va, sin medida, en sentido de lo que se halla en la cercanía. Lo que está cerca son las cosas. Al explorarlas, aparece la distinción entre lo cosivo de la cosa, vale decir, la capacidad significativa de la cosa, y la objetividad del objeto. Si la cosa es lo que está en la cercanía, lo que Heidegger pone en cuestión no es la manera de perfilar adecuadamente la cosa con que nos enfrentamos [Gegenstand], para que la representemos de un modo ajustado a su ser, sino que mostrarla como algo que se erige de manera autónoma [Selbaständiges], sostenida desde su modo de ser cosa (HEIDEGGER, 2007a, p. 235). Se trata entonces de ir en dirección del ente, de manera de dejarlo descansar en sí, en su esencia. Así, la jarra, dice Heidegger, es una cosa. Lo cósico [das dingliche] en ella reside en su ser jarra: que envasa y sirve como vasija [Gefäß], que envasa [fäßt] en sí algo, así como también lo sirve y derrama. Por lo tanto, en cuanto vasija o recipiente, la jarra está en sí. Permanece siendo vasija, independiente de nuestra representación. Sin embargo, sólo si se la emplaza de una cierta manera, la vasija puede estar en sí. La vasija demanda un producir por parte del hombre, que es un hacer estar que no constituye lo propio de la jarra como jarra. La producción tiene la tarea de conducir a que la jarra entre en lo que le es propio, poniéndola al descubierto en lo que de alguna manera ya es y de lo cual proviene, pero reconociendo con ello que lo propio de su esencia se sustrae a su gesto, ya que esta no puede ser elaborada ni producida. La desocultación en el ser no es por tanto un estado del ente, sino que una efectuación que exige del hombre una cierta participación. 
Lo envasador [Fassende] de la jarra es el vacío. Sobre él reposa aquello en lo que consta la jarra, determinando cada gesto material del producir (HEIDEGGER, 2007a, p. 239). Pero el vacío no se confunde aquí con un espacio desocupado por el que se expandiría un líquido. Asumir esa concepción aniquilaría la cosa. Nos forzaría a abandonarla en la nada, impidiéndole llegar al lenguaje, donde podría aparecer su esencia. La ciencia se ha dedicado desde siempre a este aniquilamiento de las cosas en cuanto cosas, mucho antes de la angustia que siente actualmente al confrontarse al nihilismo de su propia potencia de destrucción. Velando el vacío, que es por donde despunta y se oculta el ser, la ciencia, como la metafísica, olvida la verdad de la cosa. Por esta razón es que las cosas en cuanto cosas no han podido acceder al pensar, ni han podido reclamarlo. Para que la cosa pueda acceder al lenguaje, hay que dejar que el vacío de la jarra sea aquello en torno a lo cual se edifica su esencia, atendiendo sólo a lo envasador de la jarra y a la manera en que el acoge vacío. El envasar toma y retiene, así como también lo envasado se vierte y entrega, dando a beber. Esta doble función del vacío, hace que se reúnan en unidad de esencia los dioses y los mortales, la tierra y el cielo, que es lo que Heidegger llama "cuaterna" [das Geviert]. La esencia de la jarra "es la pura y donante reunión de la simple Cuaterna" haciendo que la jarra esencie en cuanto cosa [Ding]. La jarra es la jarra en cuanto cosa, esencia desplegándose como cosa [dingt], se demora en su ser, y así reúne y encuentra su lugar. La esencia de la jarra experimentada y pensada de esta forma es lo que hace que lleve el nombre de cosa (HEIDEGGER, 2007a, p. 244-245).

La cosa, en su carácter de cosa, abre y acerca el mundo, trenzando y articulando la estructura del sentido. Si la manera en que una cosa congrega es única, esto no se explica por sus características "propias", sino por la manera en que refleja una configuración de mundo. Mas la cosa no crea el mundo, como un centro sustancial. Lo abre a partir de la relación de reciprocidad que entablan entre sí. Sólo de esta manera la unidad de la cuaterna se despliega unitariamente. Ninguno de sus elementos puede captarse por separado, ya que cada uno refleja a su modo la esencia de los demás. Es la unidad de los cuatro desde la interacción y articulación recíproca de sus elementos, que es lo que los define al mismo tiempo que los diferencia. Este juego de espejos es el mundo, que "esencia al mundear" (HEIDEGGER, 2007a, p. 252). Lo que hace que el mundo sea mundo no puede ser una deducción. No puede explicarse mediante algo distinto, ni fundarse en algo diferente, que esa especie de desenvolvimiento de la unidad de los Cuatro, que Heidegger denomina "danzar en corro" (HEIDEGGER, 2007a, p. 253), que da lugar para, de vez 
en vez, alguien pueda ocuparse de una cosa. Que el "danzar en corro" sea el "anillo que anilla" en su simplicidad a la "cuaterna", se debe a que para Heidegger ya no se trata exactamente de la marcha circular de la hermenéutica de Ser y Tiempo, precondición de toda comprensión del ser. Ahora, de lo que se trata es del doble giro del acontecimiento unitario, como anillo que anilla. Por lo tanto, si en Heidegger existe una topología del ser [Toplogie des Seyns], con la que sería posible dar cuenta del problema del ser-lugar del lugar de la verdad, sin presuponer una comprensión de lo que eso significa, con miras a continuar con el proyecto [Entwurf] de un "extático estar arrojado en lo abierto", inaugurado en Ser y Tiempo - como sostiene Heidegger (2003, p. 41) - esa topología debería seguirse en el tránsito que va del círculo hasta el anillo, tomando como guía que para Heidegger, desde Ser y Tiempo, "[...] lo decisivo no es salir del círculo, sino entrar en él en forma correcta” (CATTANEO, 2016; HEIDEGGER, 1998, p. 176).

La esencia reunida del mundo, que anilla $[$ ring $]$ a los Cuatro, abiertos en todas las direcciones, es la vuelta [Gering], en la que se pliegan aunadamente entre sí al mismo tiempo que de una manera propia de cada uno. En la vuelta no se trata sólo de una atadura. La vuelta también desata o desanilla [entringt] la trabazón de la esencia reunida, con miras a la docilidad y ductilidad propia de cada elemento. Desde el juego de espejos de la vuelta del anillar [Gerings des Ringen] que apropia y desapropia el ser, acontece la cosa como cosa, cuyo despliegue es insignificante o de poca monta [gering]. El acontecimiento de la cosa como cosa, por su carácter, es como tal topológico. Ereignis es tal vez el concepto topológico en Heidegger, porque opera contra todo intento de darle al ser un lugar en algo más original, primitivo, básico o primordial, en un propio [eigen] más fundamental que la dinámica de apropiación y desapropiación de lo mismo (MALPAS, 2012, p. 214). Ereignis habla de la correspondencia en el mutuo destinarse del hombre y el ser. El destinar envía a la espacialidad, ya que, originariamente, según Heidegger, la palabra alemana schicken significa ordenar y preparar un espacio. El ser adviene entonces de manera espacializante. Prepara una localidad [Ort] o topos, para que el ente comparezca como tal. El ser se destina al no entregar nada más que su darse, de manera que, dando lugar, se retiene y se retira en sí mismo (DASTUR, 2007 , p. 225). Si el acontecimiento es lo que sucede en lo que sucede, como un despliegue extático de lo abierto, el acontecimiento de la cosa como cosa, advierte Heidegger, es modesto. Su gesto, prácticamente inaparente. Es incluso limitado en número, si se compara con el sin número de objetos con los que el hombre puede encontrarse en lo inmenso de su pura condición de ser vivo 
(HEIDEGGER, 2007a, p. 254). Por lo tanto, si la muerte "es el cofre de la nada" en que alberga el ser, "sólo los hombres en cuanto mortales logran, habitando, el mundo en cuanto mundo. Únicamente lo de poca monta del mundo llega alguna vez a ser cosa" (HEIDEGGER, 2007a, p. 257).

Volvamos ahora a La instancia de la letra..., teniendo en consideración la definición de cadena significante como un antecedente de aquel "voto puramente gratuito" de Lacan a Heidegger. Decíamos al comienzo que con esa definición, Lacan da cuenta con su topología de la topología heideggeriana. Sin embargo, la recepción de Lacan no es sin reparos. Ahí donde Heidegger sostiene que la relación originaria con la cosa se habría perdido en su traducción a la res latina, que desemboca en el ens, como esencia aplicable a lo presente, Lacan optará por otro modo de abordaje, otorgándole a la etimología un lugar secundario para sus pretenciones. Las consideraciones etimológicas, afirma Lacan (2008, p. 465), “[...] por muy existentes que sean para el filósofo, nos devían del lugar desde donde el lenguaje nos interroga sobre su naturaleza”. Para sostener esta interrogante, es necesario desprenderse la ilusión que conduce al postivismo lógico en su búsqueda del sentido del sentido: que el significante tenndría la función de "representar un significado" o que su existencia responde "a título de una significación cualquiera" (Lacan, 2008, p. 466). Interrogando el signo, enfatizando el papel que ahí cumple la barra "resistente a la significación" que separa sus niveles, Lacan propone que su algoritmo revela la estructura del significante. Esta estructura, como se dice corrientemente del lenguaje, es que el significante sea articulado. Lo que quiere decir que sin importar desde donde comience su análisis, las imbricaciones recíprocas y los englobamientos crecientes de sus niveles, deben someterse a una doble condición, que son las de "reducirse a elementos diferenciales últimos y de componerlos según las leyes de un orden cerrado" (LACAN, 2008, p. 468-469). La primera condición hace referencia a los fonemas, "descubrimiento decisivo de la lingüística", en los que hay que buscar la propiedad del significante como un sistema "sincrónico de acomplamientos diferenciales, necesarios para el discernimiento de una lengua dada". Con la segunda condición, se afirma como propiedad del significante la necesidad de un sustrato topológico, al que uno puede aproximarse mediante el término de cadena significante y que Lacan (2008, p. 469) define como ya vimos: "anillos cuyo collar se sella en el anillo de otro collar hecho de anillos". Este encadenamiento responde a las condiciones de estructura que determinan, en la gramática, un orden de imbricaciones que va desde los ragos distintivos y fonemas, hasta la unidad superior de la frase, mientras que 
en el léxico, establecen un orden de los englobamientos constituyentes del significante hasta la locución verbal. Esto último se se puede explicar, por ejemplo, mediante el empleo de un semantema. Debido a que no puede remitirse a sí mismo para constituirse como unidad significativa, tiene que dirigirse a su grado inmediatemente superior para encontrar su significación. Por esa posición relativa, el grado superior y el semantema adquieren estatuto significante. El uso de la lengua demuestra entonces que el patrón de búsqueda de la significación está dado por estas correlaciones, que van del significante al significante.

Ahora bien, la noción de empleo, cuando es pensada adecuadamente - considerando a la palabra como inseparable de su uso - impide detenerse en los límites estáticos en los que la gramática y el léxico permanecen. Si lo hicieramos, nos advierte Lacan, caeríamos en el error de suponer que, más allá de esos límites, la significación reinaría sin competencia en una indicación a la realidad. A esto se debe que, en opinión de Lacan, el límite en el que permanecen- que no es más que una sumatoria partes extra partes del espacio y el tiempo puros del código - no se constituya respecto de una realidad a significar, en la que el signo se completaría ordenándose con miras a un referente, sino respecto del tiempo de corte y retroacción que introduce el significante. El límite del empleo, en los confines del espacio instrumental del significante, es un tiempo de anticipación y retroacción; un tiempo de paso y de apertura de la significancia en general; tiempo introducido por el significante, desde que su naturaleza "es la de anticipar siempre el sentido, desplegando ante él mismo su dimensión” (LACAN, 2008, p. 469). La barra entre los niveles del signo se convierte en la función de corte del discurso, con el que se verifica la estructura del sujeto como discontinuidad en lo real. Esta oferta al significante - como indicará Lacan poco después en Subversión del sujeto..., retomando la cuestión - que constituye el agujero en lo real, se distribuye en una disimetría entre el lugar, en que el significante se constituye por una reunión sincrónica y numerable, y el momento de una escansión, puntuación donde la significación aparece como un producto terminado. La sumisión del sujeto al significante, que se produce en el circuito que va entre el lugar del Otro y el tiempo de su significación, es propiamente un círculo, en la medida en que "el aserto que se instaura en él, a falta de cerrarse sobre nada sino su propia escansión, dicho de otra manera, a falta de un acto en que encontrase su certidumbre, no remite sino a su propia anticipación en la composición del significante, en si misma insignificante". Mas la cuadratura de este círculo, prometida a la completitud de la batería significante, es sin 
embargo imposible, por el hecho de que "el sujeto no se constituye sino sustrayéndose a ella y descompletándola esencialmente, por deber a la vez contarse en ella y no llenar en ella otra función que la de la falta" (LACAN, 2008, p. 767). El círculo se caracteriza por hacer agujero. Tal vez por esto el grafo del deseo se abre "como un frasco" con la pregunta del Otro: ¿qué (me) quieres? (LACAN, 2008, p. 775); y el sujeto, efecto de la articulación significante, se constituye primordialmente como falta, un menos contable que requiere, para ser captado, de una topología diversa a la de la esfera.

Esta topología debe demostrarse mediante las operaciones que pueden realizarse sobre una superficie. Toda superficie, por definición, es localmente homeomorfa al plano, por lo que el toro y la esfera, cuando están sumergidas en el espacio tridimensional, son localmente idénticas para el sujeto inscrito en ellas. Dado que, además, ambas tienen la propiedad topológica de ser cerradas y bilateras, el sujeto de la superficie no puede saber, de antemano, en cuál de ellas habita. Sólo el "corte cerrado" del significante, que es al que el sujeto está identificado, es el que hará surgir la diferencia global entre las superficies. Así, mientras que, en la esfera, todo lazo puede reducirse a un punto, en el toro, hay lazos irreductibles, porque incluyen el agujero central en su círculo: el que se cierra en forma de bucle pasando a través del agujero, que Lacan llama "círculo pleno" [1] y el que circunda alrededor del agujero del toro, que llama "círculo vacío" [2]. Ambos producen una suerte de "bobina”, que simboliza la repetición de la demanda:

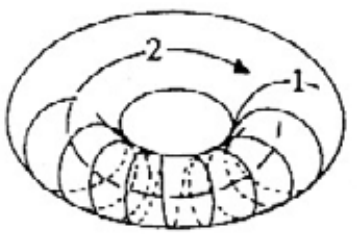

Fuente: Lacan (2012b, s/p)

El sujeto demanda el ser que se ha dado a la fuga entre enunciado y enunciación. En la cuenta de las vueltas que da su demanda, se reencuentra, pero engańado en una, como (-1). Esta equivocación se debe a que la vuelta que el sujeto no ha logrado contar, es la que ha dado dando la vuelta a la superficie. En la sucesión de los círculos llenos, los círculos vacíos, como anillos de esos bucles, unen a todos los círculos de la demanda, de manera 
que señalan al objeto metonímico que le es propuesto al deseo, pero que sólo puede ser contorneado - en todos los sentidos de la palabra, como dice Lacan (2012a), ya que contour contiene tour, que es anagrama de trou, agujero.

\section{LA “DIVERGENCIA”: EL VACío Y EL AGUJERO}

Si el vacío de la jarra, como sostiene Heidegger, no es un "dato" manipulable ni un estado de cosas al que podríamos referirnos abstractamente, es porque en el vacío es donde descansa la fundamental capacidad de acogida de la jarra. El vacío no es algo como tal, sino que un movimiento de puesta en forma. Al comentar esta cuestión en la lección del 27 de enero de 1960 de La ética del psicoanálisis, Lacan entiende que es a partir del vacío como el alfarero crea la jarra. El vacío es lo que introduce en el mundo la perspectiva de lo pleno, a través del modelamiento de aquella "nada de particularmente significado" que caracteriza la función significante de la jarra. El hecho de que para Lacan exista una identidad entre este modelamiento de un significante y la introducción en lo real de la hiancia o agujero que llama Cosa, refrenda de alguna manera la perspectiva heideggeriana de que el lenguaje no adviene como tal, sino que acontece en el transcurso de un advenimiento. El lenguaje se presenta como una especie de álito. Como un tufo que nos lanza sobre la pista de una presencia sustraída, tal como el olor de la mostaza que sube por nuestra nariz, proveniente de un tarro que, en nuestra vida práctica, no puede sino estar esencialmente vacío (LACAN, 2003, p. 148-151).

Para Lacan, así como para Heidegger, modelar un significante como nada, abrirlo sin restricciones en su significancia, es un proceso de vaciamiento. Con él se efectúa la delimitación de un umbral que agujerea, como un entramado en torno de lo que nunca se presenta en cuanto tal y que no aparece sino como la nada que acompaña a todo lo ente, que es el ser. Este umbral no divide, simplemente, el afuera del adentro, sino que constituye al ser como un pliegue que se despliega en el lenguaje, manteniendo la diferencia ontológica como una división irreconciliable. En la manera en que se entiende el ser como nada, está lo que, en definitiva, podría llegar a obliterar el modelamiento del vacío que determina el habitar el lenguaje. En esto, Lacan y Heidegger parecen coincidir. Sin embargo, una de las cuestiones más díficiles de abordar, cuando se trata de considerar, una al lado de la otra, la perspectiva lacaniana y heideggeriana, es el problema de si esa hiancia del ser hace resonar o no el llamado de una profundidad originaria. Como veíamos más arriba, 
anunciado por Lacan en la Instancia de la letra, que la topología lacaniana tome otro sentido que aquel hacia donde conduce la etimología a la topología hedieggeriana podría encontrar aquí su razón. Ese otro sentido debemos buscarlo en un tonel distinto que la jarra de La Cosa, que se encuentra en el curso de Heidegger en la Universidad de Friburgo del semestre invierno del 51'-52', ¿Qué significa pensar?

La pregunta ¿qué significa pensar? puede ser abordada de cuatro maneras, nos dice Heidegger. Desde el significado de la palabra "pensar"; mediante la manera en que la tradición ha entendido el rasgo fundamental del pensamiento que es la lógica; desde el examen de los requerimientos para pensar adecuadamente; y, por último, considerando lo que nos llama al pensamiento. Estos cuatro abordajes se pertenecen entre sí y se elucidan si se considera el último abordaje como el más decisivo para abordar la cuestión. Lo que quiere decir "pensamiento", es lo que nos quiere decir. Es un acusativo, que convierte a la pregunta en una indagación sobre aquello que por primera vez nos remite al pensamiento y que nos afecta, porque nos llama, a nosotros mismo, a nuestra esencia. Nosotros somos los interpelados, los que comparecemos en el tejido de la pregunta (HEIDEGGER, 2008, p. 113-115). Pero lo que nos llama al pensamiento sólo puede hacerlo en cuanto lo que llama requiere del pensamiento; lo que llama a nuestra esencia necesita de la actividad del pensar. Lo que llama al pensamiento debe ser cuidad en su propia esencia, por lo que es lo que nos da que pensar. El mandato es lo debe ser pensado, y lo que todavía no pensamos, porque es lo que da que pensar. El pensar debe abrirse a lo que lo constriñe y empuja como una fuerza exterior, ponerse en camino hacia ello preguntando, si no quiere permanecer ciego al envío de nuestra propia esencia occidental a tomar la forma del logos que enuncia. Si el pensamiento todavía no piensa, si eso es lo que más nos da que pensar, es porque se piensa siempre ya ahí, mientras que es entre el todavía no y el ya ahí, en su imposibilidad ontológica, donde alberga el espacio de juego de nuestra esencia. Lo que da que pensar ya habla en el pensamiento, antes de que este pueda ponderarlo y ponerlo ante sí como una representación, es lo que el pensar todavía no piensa y lo que le llama a pensar. Es esta latencia la que entrega al pensar un lugar habitable al mismo tiempo que inhóspito, que lo pone en un equilibrio inestable entre logos e historia. Porque pensar que todavía no pensamos no implica que se lo vaya a lograr hacer. Que todavía no hayamos entrado en el ámbito de lo que quisiera se pensado aun cuando ya estamos ahí, no es un descuido o un atraso del hombre. Se debe a que lo digno de ser pensado se aparta y se ha apartado siempre del hombre. Y ante esta incertidumbre, 
parece estar siempre al acecho la tentación de preservar una especie de fondo originario de propiedad, que pueda sostener el acontecimiento del ser.

El acontecimiento propiamente tal de la historia obra en la historia. Se da y permanece replegado en ella. Lo que da que pensar y determina la esencia del pensamiento no se alejó del hombre en un momento fechable, sino que se ha mantenido siempre en ese alejamiento. ¿Qué significa pensar? se transforma entonces en la pregunta histórica, porque apunta al comienzo del pensamiento occidental, señalando, con la determinación de la diferencia ontológica, la manera de pensar nuestra época (HEIDEGGER, 2008, 146). Lo que hace que para Heidegger la historia del ser es una, se debe a que el ser es aquello de lo que no hay una segunda vez. Como nada hay que se corresponda originariamente al ser, el ser se da de la misma manera al comienzo y al final de la historia: como remisión. Los presocráticos no son por tanto el verdadero origen recobrado de la historia, sino quienes respondieron pensando al desplazamiento inicial que llama al pensar. Será en el decir donde Heidegger formulará la pregunta por la historia como un todo, por su comienzo y su final, su dirección, sus puntos de viraje y su relanzamiento con miras al ser. Es en el lenguaje donde puede ponerse en juego esa falta de correspondencia o identidad, debido a que no hay un significado original del ser. Con el decir podrá renovarse el gesto de ir hacia las fuentes sepultadas por la metafísica, renovando la respuesta al desplazamiento de la aurora. Heidegger intenta mantener así una relación con lo originario, rota por la manera en que la tradición tradujo lo griego. La traducción de los nombres griegos a la lengua latina es la ruptura de esa relación y el comienzo del destino metafísico de Occidente. Es que el pensamiento romano, simplemente adopta las palabras griegas, dice Heidegger, despojándolas de las experiencias originales que estas dicen. El pensar occidental pierde por ello un terreno firme donde pensar, así como la oportunidad de torcer su destino metafísico. El decir debe sobrevenir e irrumpir en la historia para traer de vuelta esa experiencia, que es la del pliegue del ser. Como un desgarro en los sedimentos de la tradición ontológica, alcanza al hombre en su esencia, siguiendo el trazo del primer envío del ser.

Desde el espacio de un "juego de lenguaje", hacia el que se orienta nuestra esencia, pueden abrirse las palabras que hablan en lo hablado. Poetizar y pensar son el decir esencial, con el que el hombre se arriesga a recibir el don del ser. El decir esencial habla el lenguaje, en vez de utilizarlo como medio de expresión. Como el poetizar y el pensar dicen las palabras, tan pronto se toma su camino con el fin de que el lenguaje hable a través del hombre, uno 
se ve obligado a atender al decir propio de las palabras. Si las palabras son habladas y oídas, pareciera que su captación sensible en el sonido sería algo captado inmediatamente, mientras que la significación o el sentido de las palabras, a las que estas estarían unidas, sería su componente no sensible. Por esta razón es que se habla de actos que tendrían la labor de dotar de sentido al sonido desnudo. Las palabras estarían así llenas de sentido. Se las considera "como cubos o toneles", especie de cajas de resonancia de las que sería posible, penetrando en su interior, extraer una significación. Sobre esta representación, que separa lo inteligible del significado de lo sensible de la configuración sonora, podría hacerse un juicio sobre el pensar que presta atención a las palabras. Pero la inmediatez del sonido es sólo una configuración abstracta hecha para comprender lo que significa atender al decir de las palabras. Y lo inmediato no es lo próximo, sino sólo lo acostumbrado. Lo representado como pura dimensión acústica es una mediación abstracta, porque el sonido no se oye por sí mismo. Nunca se oyen puros sonidos, sino sólo palabras incomprensibles. Pero tampoco se nos presentan en primer lugar meras palabras. Entre una y otra se sitúa el abismo de una diferencia esencial, en el que el oír debe demorarse. Porque atender al decir significa demorarse en el espacio de juego de lo hablado antes que en la palabra o el sonido como tales. Las palabras, entonces, no son toneles de donde podría sacarse algo, sino que "son fuentes que el decir excava, fuentes que han de encontrarse y excavarse siempre de nuevo, que con facilidad quedan sepultadas" (HEIDEGGER, 2008, 125-126). En las palabras puede volver a relanzarse la historia, renovarse el gesto de ir a la fuente, para que el contenido del tonel no quede estancado.

Pero en este ímpetu, la excavación heideggeriana no se abstiene de cualificar los estratos que reconoce, con la finalidad de evitar la caída en el sentido cotidiano y vulgar del que con dificultad nos desprendemos. Es como si con ello, Heidegger retrocediera ante la topología de esa duplicidad esencial que tan bien supo reconocer. Sus toneles están agujereados, más no vacíos del todo. El espacio del lenguaje, que retoma las palabras estancadas en su movimiento, conduce a la historia de la lengua. Para que Heidegger llegue a afirmar que la pregunta por lo que significa [heißen] pensar, significa a su vez lo que manda [heißen] al pensamiento y lo pone en camino a su esencia, no es suficiente la cifra significante. Heidegger parece llevado a suponer que las significaciones vulgares o comunes descansan sobre otras, las "auténticas, iniciales y decisivas" (HEIDEGGER, 2008, 126), que son las que conducen, a partir del claro abierto por la lengua alemana, hacia el milagro griego. La identidad entre pensar y poetizar aparece como una orientación hacia el 
origen, hacia el comienzo y hacia lo auténtico. Escuchando la poesía, que da a escuchar más de que lo que se puede entender, el pensar logra situarse bajo el influjo de una existencia histórica inicial, y corresponder a un lenguaje originario que puede decir más allá de la palabra dicha. Esta identificación entre pensar y poetizar, constituye un decir que deja pensar el ser al origen, vale decir, el tener lugar de la diferencia ontológica. Una orientación para el Ereignis es la que Heidegger aquí decide. Una dirección del tener lugar del acontecimiento de la verdad, que, en vez de conducir al abismo de la palabra, lo escamotea. Casi una década antes de Le Thor, la "topología" hacía su primera aparición coronando esta dificultad, en el pequeño opúsculo Desde la experiencia del pensar, en el que Heidegger la definía como una "poesía que piensa”.

El lugar en que las palabras se abren en lo hablado, en la topología lacaniana se constituye y se organiza por la irreductibilidad del corte significante. Con él, comienza el derrame de la significancia de un decir que no puede clausurarse en lo dicho. Porque el corte actúa en el lugar donde el "sentido del sentido" busca encontrar su reaseguro, tratando de reducir, a través de la tautología, la metonimia de la significación. El corte producido en el "decir lo mismo", con el que se recolectaría la palabra en el concepto, hace del segundo término, aquel en que se sostiene la mismidad, el significante del corte, entregándolo a la no identidad consigo mismo del significante. Ahí donde la palabra intenta "lógicamente" recogerse en su verdad y constituir una unidad de sentido, el corte entorna una fractura, enlaza un binario que la lengua no puede velar, pero sí cifrar. Con esto, retomamos el hecho de que la llamada de atención de Lacan a Heidegger en la Introducción alemana.... repare en el problema del agujero por donde huye el sentido. Se trata de la "necedad" del significante, desarrollada por Lacan en la lección del 19 de diciembre de 1972 del seminario Encore. Allí, para explicar cómo funciona un significante, en su diferencia con el significante, vale decir, para exponer la diferencia entre una función del significante que podría totalizarse, fundándose en un predicado, y una que no, Lacan ya no sólo se referirá a la frase, para pensar la estructuración topológica del significante, sino que a la "función proverbial". En el proverbio, la significancia, dice Lacan, "se abre en abanico", como lo demuestra à tirelarigot, que "quiere decir" a paladas o a raudales. Sin embargo, cuanto más sentido se pone en esta expresión, cuanto más oído se pone en ella con el fin de captar su sentido, tanto más se lo aprehende en su retirada. Porque luego de "la construcción y la fabulación", que hasta se inventa "un señor llamado Larigot" que habría existido en algún momento de la historia, la pregunta 
permanece. ¿Qué quiere decir entonces? Nada más, sentencia Lacan, que su puesta en signo. À tire-larigot, "la zambullida del deseo en el tonel perforado de la significancia” (LACAN, 2010).

El sentido huye por el tonel perforado de la significancia (LACAN, 2010). Por ello, la morada en que habita el "ser" hablante, se caracteriza por ser "fofa" [cotoneaux] (LACAN, 2012a, p. 580). Es que el "ser" no puede sino inevitablemente caer hacia toda suerte de toneles, sumergirse en toda clase de conceptos, dado que la palabra como el concepto abrevan en la misma falla de la lengua, que transporta y marca el decir. El proverbio sería entonces una dimensión fútil de la palabra, que sólo retiene el agujero que la sexualidad, por su incapacidad para revelarse, hace a la verdad. Ni autentica, ni inicial ni decisiva, la necedad, a la que el filósofo pareciera hacer oídos sordos, demuestra que, en la dimensión abierta por el significante, el ser ya está perdido; antes que, destinado, lanzado al azar de los encuentros. Esto es lo que explica que el método freudiano coloque al discurso bajo la determinación de sus ocurrencias, die Einfälle, de lo que cae [fallen], sin mediación, fuera de él; las ideas le caen delante, súbitamente y de improviso, por lo que ni la interpretación ni las asociaciones [Assoziation] podrán adelantarse a lo vendrá del inconsciente (GOLDSCHMIDT, 2017, p. 41-42; FREUD, 2010c, p. 275).

$\mathrm{Si}$ es el corte significante lo que revela el agujero que organiza la estructura, es necesario reconocer buenos y malos cortes: los que recorren el agujero y los que lo escamotean. La topología del ser hablante quedaría así supeditada de la eficacia del buen corte, con que se reabre la fuga del tonel. Esto no niega que el psicoanálisis pueda entregarle al analizante el sentido de sus síntomas, aclara Lacan. Lo que pone en cuestión es que la experiencia de ese traspaso pueda sumarse a otras. A esto se debe que, en un análisis, todo haya de ser recogido como si nada hubiera quedado establecido en otro lado, "lo que solamente quiere decir que la fuga del tonel debe ser siempre reabierta" (LACAN, 2012a, p. 583). Abrir lo abierto de la buena manera, implica que para que el ser hablante llegue a habitar el lenguaje, le es preciso ex-sistir, y la existencia, para Lacan, embraga en el real de la no relación sexual, único real que no logra inscribirse en la dimensión de la palabra. Es la conformación y delimitación de un espacio de captura, de Begriff, de encierro entre-dos del concepto (entre la forma y el contenido) o del signo (entre el sonido y el sentido), lo que efectúa el agujero que abre interiormente ese espacio, exponiéndolo a la fuga del sentido. No hay que desdeñar por tanto la aclaración de Lacan en su Introducción, de que la fuga no es una 
escapada (LACAN, 2012a, p. 579). Porque no se trata para él de abandonar el espacio del signo/tonel en nombre del sentido y de un decir esencial, sino de comprender lo que funda y desfonda esa localidad.

El sentido se capta porque huye; hay sentido porque hay fuga. Cuando los elementos del signo son ubicados con miras a su relación, estos suscitan un tercer elemento, con el que esa relación podría inscribirse. Sin embargo, los efectos de significado, empujados por el significante que los causaría, le yerran a ese referente. $\mathrm{O}$, para decirlo de otra manera, el referente, como tercero, surge por el errar, a partir de lo cual, podría exigirse, que la relación sea susceptible de ser inscrita. Sin embargo, llevado al límite, el significante no opera por su capacidad para sustituir una significación que se ausenta y a la que sólo podemos aproximarnos por tanteos sucesivos, sino por inscribir esa falta en lo real. El "encuentro fallido" con el "buen referente", que por ese mismo yerro localiza y especifica ese referente como real, es aquí lo constitutivo de los efectos de verdad en el inconsciente. Es por tanto la cifra, y no la cuenta, lo que funda el orden del signo y lo que exige, del saber, delinear los contornos de los efectos de verdad que se entregan en las formaciones del inconsciente. El inconsciente trabaja sin pensar en ello, sin juzgar ni calcular. Simplemente hace su trabajo de cifrado, que es preciso deshacer en el desciframiento. Lo que el psicoanalista debe saber es que hay un saber que no calcula, "pero que no por ello trabaja menos para el goce” (LACAN, 2012a, p. 585). El cifrado es del orden del goce sexual, que es lo que queda fuera de lo que sirve. El goce, al estar en el cifrado, encadena la no relación con la intrusión de lo real, como un accidente en el orden del pensamiento que afecta al cuerpo. Del goce, que hace obstáculo a "la relación sexual establecida", el lenguaje no deja otra huella que un "zigzag infinito" (LACAN, 2012a, p. 582).

Desembocar en el sentido no impide entonces que este, como sostiene Lacan, haga agujero. Haber acertado con una interpretación no hace que los analistas "estén en lo verdadero". Porque aun siendo justa, "sus efectos son incalculables" (Lacan, 2012, p. 585). Todo el lenguaje es nada más que cifra, en el sentido en que Lacan lo enuncia del inconsciente: que se descifra. Una topología que desconozca esto, no puede sino quedar prendada en la labor de prolongar la historia de la metafísica. Inscribe en un destino histórico la relación que el lenguaje no inscribe, poniendo el real por fuera del lenguaje, velando el agujero de la política. Desde el momento en que la historia suplementa el juego entre cifrado y descifrado, el tercero excluido es el que dicta la norma y organiza una jerarquía ontológica de las lenguas. Este parece ser el caso 
de la topología heideggeriana, cuando parece decidirse por un "lenguaje originario", que dice más allá de la palabra dicha. Este hace con el lenguaje lo que la metafísica siempre ha hecho: velar el abismo inherente a la identidad al sostener la identidad entre pensar y poetizar. La decisión de Heidegger repite la "decisión sobre el sentido", inaugural de la metafísica (CASSIN, 2013, p. 92). Cuando es posible apropiarse del lenguaje y utilizarlo, asumiendo un origen o principio - que no es otro que el "indemostrable" principio de no contradicción - es posible, de la misma manera, apropiarse de la polis en la que habitan los sujetos hablantes. Estratificando las significaciones en vulgares y originarias, superficiales y profundas, inevitablemente se decide lo que quiere decir hablar, y también lo que es, y no es, un ser dotado de logos.

El hombre habita lo inhabitable, porque en el lenguaje no es posible permanecer como subjetividad. El lenguaje es división consigo mismo transportada por el decir. Así, la polis, como el espacio vacío en torno al cual se congrega una comunidad política, puede identificarse a este "defecto" constitutivo del lenguaje. Esto explica que, para Heidegger, la polis, como "el paraje esencial del hombre histórico", no se deje determinar políticamente (HEIDEGGER, 2005, p. 124). Sin embargo, cuando esa división es cubierta, confundiendo lengua y pueblo, el lenguaje se rebaja a un cúmulo de enunciados, que dictaminan que una comunidad política está por sobre otra; que hay modos privilegiados en el ser que aparece para una y para otra, aseverando que existe una jerarquía en la polis por el logos; que el Estado puede sustituir y representar a la polis, identificando el lugar del lenguaje y el espacio de la ciudadanía; y que, finalmente, lo inhabitable, o lo "fofo" de la morada del hombre como dice Lacan, antes que una dimensión ontológica de la existencia, se transforma en una "vara" moral y política, con que se mide "lo que vale” el sentido (LEYTE, 2008, p. 266-270; CAPUTO, 1993, p. 109).

En su curso de Friburgo del 34'-35' sobre los himnos de Hölderlin Germania y El Rin, Heidegger escuchaba que el Dasein histórico de los pueblos, su asunción, ocaso y apogeo surge desde la poesía y, de ella, el auténtico saber en tanto que filosofía y, de su conjunción, la realización del Dasein como pueblo a través del Estado y de la Política. Con Hölderlin, el decir original adquiere la forma del mito. "Mitología del acontecimiento" como la ha llamado Christian Sommer (2017), que permea ¿Qué significa pensar? y que parece estar a la base de la topología del ser. Para Heidegger, el mito es el decir original en el fundamento del logos, que ha permanecido impensado o no advenido del griego. Interpretando los himnos de Hölderlin, la "poesía que 
piensa" funda el espacio-tiempo de la verdad del ser. El originario tiempo histórico de los pueblos es, por tanto, el tiempo del poeta, del pensador y del estadista, "que auténticamente fundan y fundamentan el Dasein histórico de un pueblo. Ellos son los auténticos creadores" (HEIDEGGER, 2010, p. 5758). Con Hölderlin, Heidegger se propone "crear nuevamente un espacio y un lugar en nuestro Dasein histórico, para lo que la poesía es". Porque Hölderlin - y en esto Heidegger sigue sin reparos la ya hace mucho tiempo cuestionada recepción del poeta inaugurada por Norbert von Hellingrath - es el "poeta del poeta” en cuanto es poeta de los alemanes. Pero ese lugar está oculto todavía. Aún no lo es, pero debe llegar a serlo. Porque la poética de Hölderlin es, como el mismo afirmara, una filosofía de la historia. Una ley, como interpreta Heidegger en su comentario de Andeken, determina el camino adecuado para que el poeta retorne a lo que es más propio (HEIDEGGER, 2018, p. 116118). Sólo así, "la Política es inscripta en el más elevado y auténtico sentido" (HEIDEGGER, 2010, p. 189-190).

\section{Conclusión}

En la lección del 8 de abril de 1975 de R.S.I., Lacan recuerda para su auditorio la última visita que hizo a Heidegger. Había ido a enseñarles sus nudos. Porque para eso sirve el signo, les dice a los presentes ese día en su seminario, para hacer nudos. Y el nudo borromeo, como ya lo había demostrado Lacan dos años antes, en la lección del 15 de mayo de 1973 del seminario Encore, se anuda en el lugar del toro. El toro, decía Lacan entonces, es la razón del nudo, porque lo permite (Lacan, 2010). Lo que Lacan trataba de enseńarle a Heidegger en ese último encuentro, como también lo hacía con el auditorio de su seminario aquel día de abril, es que en los nudos hay una praxis, una manera de hacer, que podría conducir al parlêtre a dejar de creer en el ser por fuera del ser de hablar. Es que el parlêtre cree, dice Lacan, porque habla. $\mathrm{O}$, mejor dicho, parlotea en su necedad, al deslizarse por el equívoco entre parlêtre y parlote. Pero debido a que habla, no será en un dios donde encontrará su "salvación", sino que en su errar, porque es del lenguaje de donde "recibimos esa locura de que haya ser". El ser hablante sólo existe como parlêtre en el errar [erre] de su existencia, limitada por el rasgo unario [unaire] que escande y escinde la experiencia como corte y pérdida. Se debe a "la buena filosofía” de Heidegger tanto como a Freud, sin importar que al primero no le 
interesara en nada el segundo ${ }^{2}$, que, en opinión de Lacan, algo haya emergido, permitiéndole al psicoanalista "existir un poco más" al apretar el nudo (Lacan, 2002). Se trata del objeto a, que es contra lo que las tres consistencias del nudo borromeo se aprietan para delimitar la creencia y la locura del parlêtre, para que este pueda existir en la senda de sus trazos residuales, en las "hiancias del ser" o en la escansión de ese "poco más" con que se modula su existencia, y que antecede tanto al pensar como al lenguaje predicativo. Pero ante ello, como bien lo sabía Lacan, Heidegger no podía, o no quería, detenerse. Lo que Lacan no podía aceptar, y que parece no haber dudado en "comunicarle" a Heidegger haciéndole una última seña con sus nudos, es que lo abierto siempre lo esté, ahí, a la espera. Porque intentar permanecer en un abierto no configurado, al no ser sostenible esa permanencia como tal, es lo que introduciría subrepticiamente la esperanza de que quizás algo pueda salvarnos de nuestra caída, y que, finalmente, logre configurar lo inabarcable de ese lugar errante, rebajándolo a ser un espacio a su medida. Tratar de permanecer en lo abierto, hacer de la instancia que horada la identidad una estancia que la sostiene en lo indeterminado, confundiría el hiato que da lugar con una figura anhelada que podría llegar a ubicarse en él. A la espera, cualquier seña sería suficiente para hacer aparecer a un Otro del Otro como instancia de apropiación a expensas de lo ajeno, cuando, para Lacan, de lo que se trata en el análisis, es de vaciar al Otro de todas las garantías que le son supuestas, de interrogar su demanda

2 Es posible matizar esta apreciación de Lacan acerca del "interés" de Heidegger por Freud al menos de dos maneras. Es de amplio conocimiento que en los Seminarios de Zollikon Heidegger se dedicó a algunos aspectos de la Metapsicología freudiana, concluyendo que esta no es otra cosa que el traslado de la filosofía neokantiana al ser humano (Heidegger, 2006, p. 303). Si el inconsciente es una hipótesis de trabajo, con el inconsciente el psicoanálisis no piensa, sino que piensa acerca del pensar, es decir, se dedica a hacer su lógica. Por lo tanto, para Heidegger, para el psicoanálisis el pensar son enunciados acerca de algo, por lo que es una logística. Pura administración científica de comunicación e información, por lo tanto, decidida a asegurar, como ya decía en ¿Qué significa pensar? el cerco de una felicidad igual para todos. Heidegger nunca tuvo otra opinión respecto del psicoanálisis. Cada vez que se refirió a él como lo hace, por ejemplo, en Introducción a ¿Qué es metafísica? (Heidegger, 2000, p. 303) o en Ciencia y meditación (Heidegger, 2007, p.178) - lo hizo en términos generales, volviéndolo indistinguible de la sociología y de la psicología. Si esto es lo que le interesaba a Heidegger del psicoanálisis, entonces, efectivamente, el psicoanálisis no le interesaba. Ahora bien, lo que recién comienza a salir a la luz, es que este "interés" por el psicoanálisis tenía como trasfondo una consideración política al menos sorprendente, que es lo que puede observarse claramente en algunos pasajes de los Schwarze Hefte. Allí, el psicoanálisis ya no es logística, sino que hace parte de la "maquinación" en la que todo es pensado como "expresión de la vida". Debido a su "judeidad", el psicoanálisis representa aquello que el nacional socialismo es incapaz de superar, independiente de los intentos de "transformación aria" de los conceptos fundamentales del psicoanálisis. Para Heidegger, el psicoanálisis representa entonces, en el plano onto-histórico, la forma más radical del pensamiento racial y, justamente por ello, un poderoso enemigo. Para comprender esta cuestión y desarrollarla más ampliamente, los trabajos de Peter Trawny (2014, p. 67-70) y sobre todo los de David Farrell Krell (2015, p. 143-146) resultan de enorme valor. 
como emanando desde un fondo originario de propiedad, con el fin de hacer advenir un "Otro sin llamado" (Allouch, 2013, p. 86). Bajo estas condiciones, el voto de Lacan, como él mismo lo reconoció, no podría haber sido sino "puramente gratuito". Nada cabía esperar como respuesta.

CATTANEO, G. Metaphysics and the hole of politics: the meaning of topology, between lacan and Heidegger. Trans/formlação, Marília, v. 43, p. 123-144, 2020. Edição Especial.

\begin{abstract}
Taking as a motive a conjecture of Lacan directed to Heidegger, referred to what would be the metaphysics and what would determine its history and its effects, the present work tries to put in relation the Lacanian topology and the Heideggerian topology. Where Lacan translates Heidegger, we will see that what appears, and that seems to have gone unnoticed, is the topological question of the hole and the political effects involved in watching it. In short, when it takes to its ultimate consequences what it means to inhabit the language, we will see that the sense that both authors print to their topology, after agreeing, diverges
\end{abstract}

Keywords: Metaphysics. Hole. Politics. Meaning. Topology.

\title{
REFERENCIAS
}

ALLOUCH, J. El sexo de la verdad. Buenos Aires: Cuadernos de Litoral, 1999

ALLOUCH, J. Prisioneros del gran Otro. Buenos Aires: El cuenco de Plata, 2013.

CAPUTO, J. D. Demythologyzing Heidegger. Indiana: Indiana University Press, 1993.

CASSIN, B. Jacques el sofista. Lacan, logos y psicoanálisis. Buenos Aires: Manantial, 2013.

CATTANEO, G. Topología del ser, topología del sujeto. Un diálogo entre Martin Heidegger y Jacques Lacan (Tesis de Doctorado). Santiago: Universidad de Chile, 2016.

DASTUR, F. Heidegger, la question du logos. Paris: VRIN, 2007.

Farrell Krell, D. Ectasy, Catastrophe. Heidegger from Being and Time to the Black Notebooks. Suny: New York, 2015.

FREUD, S. $35^{\circ}$ Conferencia de Introducción al Psicoanálisis. En torno a una cosmovisión. En S. Freud. Obras completas de S. Freud: Nuevas conferencias de introducción al psicoanálisis y otras obras 1932-1936 (J. L. Etcheverry, Trad., Vol. XXII, págs. 146-168). Buenos Aires: Amorrortu, 2010a. 
FREUD, S. Sobre el sueńo. En S. Freud. Obras completas de Sigmund Freud: La interpretación de los sueños (segunda parte). Sobre el sueño. 1900-1901. (J. L. Etcheverry, Trad., Vol. V, págs. 613-668). Buenos Aires: Amorrortu, $2010 \mathrm{~b}$.

FREUD, S. La sexualidad en la etiología de las neurosis. En S. Freud. Obras completas: Primeras publicaciones psicoanalíticas (J. L. Etcheverry, Trad., Vol. III, págs. 251-277). Buenos Aires: Amorrortu, 2010c.

GOLDSCHMIDT, G.-A. Cuando Freud vio la mar. Freud y la lengua alemana. (N. Bornhauser Neuber, Trad.) Santiago: Metales Pesados, 2017.

HEIDEGGER, M. Ser y Tiempo. (J. E. Rivera, Trad.) Santiago: Universitaria, 1998.

HEIDEGGER, M. Introducción a ¿Qué es metafísica? En M. Heidegger. Hitos (H.

Cortés, \& A. Leyte, Trads., págs. 299-313). Madrid, 2000d.

HEIDEGGER, M. Four Seminars. Le Thor 1966, 1968, 1969, Zähringen 1973.

Indiana: Indiana University Press, 2003.

HEIDEGGER, M. Parménides. (C. Másmela, Trad.) Madrid: Akal, 2005.

HEIDEGGER, M. Seminarios de Zollikon. (Á. Xolocotsi, Trad.) México: Herder, 2006.

HEIDEGGER, M. La Cosa. En M. Heidegger. Filosofía, ciencia y técnica (F. Soler, \& J. Acevedo, Trads., págs. 233-257). Santiago: Universitaria, 2007a.

HEIDEGGER, M. Ciencia y meditación. En M. Heidegger. Filosofía, ciencia y técnica (F. Soler, \& J. Acevedo, Trads., 5a ed.). Santiago: Universitaria, 2007b.

Heidegger, M. ¿Qué significa pensar? (R. Gabás, Trad.) Madrid: Trotta, 2008.

HEIDEGGER Heidegger, M. Los himnos de Hölderlin “Germania” y “El Rin”. (A. C. Merino Riofrío, Trad.) Buenos Aires: Biblos, 2010.

HEIDEGGER, M. Hölderlin’s hymn “Remembrance”. (McNeill, W y Ireland, J. Trad.). Indiana: Indiana University Press, 2018.

LACAN, J. Seminario 22 (1974-1975) R.S.I. (Versión Crítica. Establecimiento del texto, traducción y notas de Ricardo E. Rodríguez Ponte). Buenos Aires: Paidós, 2002.

LACAN, J. El seminario de Jacques Lacan: libro 7: La ética del Psicoanálisis. (D. Rabinovich, Trad.) Buenos Aires: Paidós, 2003.

LACAN, J. La instancia de la letra en el inconsciente o la razón desde Freud. En J. Lacan, Escritos 1 (T. Segovia, Trad., págs. 461-495). Buenos Aires: Siglo XXI, 2008a.

LACAN, J. Función y campo de la palabra y el lenguaje en psicoanálisis. En J. Lacan, Escritos 1 (T. Segovia, Trad., págs. 231-309). Buenos Aires: Siglo XXI, 2008b.

LACAN, J. Subversión del sujeto y dialéctica del deseo en el inconsciente freudiano. En J. Lacan. Escritos 2 (págs. 755-787). Buenos Aires: Siglo XXI, 2008 b. 
LACAN, J. Seminario 20 (1972-73) Otra vez/Encore. (Versión Crítica. Establecimiento del texto, traducción y notas de Ricardo E. Rodríguez Ponte). (R. Rodríguez-Ponte, Trad.) Buenos Aires: Paidós, 2010.

LACAN, J. Introducción a la edición alemana de un primer volumen de los Escritos. En J. Lacan, Otros Escritos (G. Esperanza, \& G. Trobas, Trads., págs. 579-588). Buenos Aires: Paidós, 2012a.

LACAN, J. Seminario 9 (1961-1962) La identificación. (Versión Crítica.

Establecimiento del texto, traducción y notas de Ricardo E. Rodríguez Ponte). (R.

Rodríguez Ponte, Trad.) Buenos Aires: Paidós, 2012b.

LEYTE, A. La casa del ser y otras casas inhabitables. En F. Duque. Heidegger. Sendas que vienen. (págs. 249-280). Madrid: Círculo de Bellas Artes, 2008.

MALPAS, J. Heidegger and the thinking of place: explorations in the Topology of Being. Massachusetts: MIT, 2012.

SOMMER, C. Mythologie de l'événement. Heidegger avec Hölderlin. Paris: PUF, 2017.

TRAWNY, P. Heidegger et l'antisémitisme. Sur les “Cahiers noirs”. Paris: Seuil, 2014.

Recebido: 16/01/2019

Aceito: 23/10/2019 